\title{
Prognostic factors for respiratory sickness absence and return to work among blue collar workers and office personnel
}

\author{
E C Alexopoulos, A Burdorf
}

\begin{abstract}
Objectives-To analyze factors that determine the occurrence of sickness absence due to respiratory disorders and the time it takes to return to work.

Methods-A longitudinal study with 2 year follow up was conducted among 326 male blue collar and white collar workers. The survey started with an interview on respiratory complaints and spirometry. Sixty six (21\%) workers were lost to follow up. Complete data on sickness absence among 251 workers during the follow up were collected from absence records and self reports. Regression analysis based on a proportional hazards model was applied to identify risk factors for the occurrence and duration of sickness absence due to respiratory disorders.
\end{abstract}

Results-During the follow up 35\% workers attributed at least one period of sickness absence to respiratory complaints, which accounted for $14.2 \%$ of all days lost. A history of chronic obstructive pulmonary disease (COPD) did not predict sickness absence for COPD; the same was true for chronic non-specific lung disease (CNSLD). Complaints about asthma contributed significantly to absence due to asthma (relative risk (RR) 3.96; 95\% confidence interval (95\% CI) 1.99 to 7.90$)$. Job title was a significant predictor of sickness absence due to respiratory complaints. Decrease in forced vital capacity (FVC, $<80 \%$ of the reference value) was also a significant predictor of absence due to asthma (RR 4.03 ; $95 \%$ CI 1.41 to 11.54 ) and of respiratory absence (RR $2.49 ; 95 \%$ CI 1.07 to 5.79). Absence with respiratory complaints was not associated with age, height, body mass index, or smoking. Duration of employment was a weak almost significant predictor against respiratory absenteeism (RR 0.94; 95\% CI 0.91 to 0.97 ). Return to work after respiratory absence was worse for blue collar workers than office personnel (RR 5.74; 95\% CI 1.90 to 17.4 for welders, and RR 6.43 ; $95 \%$ CI 2.08 to 19.85 for metal workers).

Conclusions-Asthmatic complaints in the 12 months before the study were associated with sickness absence for these complaints during the follow up. An abnormal level of FVC also influenced respiratory absenteeism. Blue collar workers had more often and more prolonged absences due to respiratory disor- ders than white collar workers. Workers with absence due to respiratory complaints were at higher risk of subsequent sickness absence in the next year. (Occup Environ Med 2001;58:246-252)

Keywords: respiratory complaints; sickness absence; return to work

During the past few decades the interest in occupational lung diseases has slowly moved from pneumoconioses to chronic non-specific lung disease (CNSLD). This comprises asthma and chronic obstructive pulmonary disease (COPD), and is characterised by airflow obstruction and symptoms such as shortness of breath, wheezing, chronic cough, and chronic phlegm production.

Respiratory disease in various occupational populations is an important cause of temporary disability as expressed by sickness absence both in men and women. ${ }^{1-4}$ Although a significant proportion of absenteeism is due to influenza and upper respiratory tract infections, CNSLD, because of its chronic course, is easier to detect and prevent in surveillance of a working population.

Monitoring of sickness absence is an essential part of occupational health care. Although sickness absence is not a simple function of ill health and also includes psychosocial factors and coping behaviours it may still be a valuable measure to assess the impact of respiratory complaints or other possible predictors of a worker's capacity. However, very few studies focus on this aspect compared with the many publications on occupational asthma and COPD. This may reflect the preference of researchers and publishers for aetiological and diagnostic instead of prognostic research.

A few studies have indicated that sickness absence is indeed higher in workers with respiratory symptoms. In an early survey among electrical workers chronic cough, diminished forced expiratory volume, and chronic phlegm production were documented as possible predictors of days of sickness absence due to respiratory illness. ${ }^{5}$ A study among workers at a fertiliser factory showed that subjects with persistent chronic cough and phlegm production had a higher frequency and duration of sickness absence due to chest diseases than workers without these symptoms. ${ }^{6}$ One study on male employees of telephone companies added marked shortness of breath and chronic wheeze to the list of possible predictors of days of respiratory sickness absence. ${ }^{7}$ In a cross sec- 
tional study in the animal feed industry the same findings were confirmed. ${ }^{8}$

In the current longitudinal study prognostic factors for sickness absence due to respiratory symptoms were evaluated. The aim of the study was to describe the frequency and duration of sickness absence due to respiratory disorders, and to investigate which factors influence the occurrence of respiratory sickness absence and the time it takes to return to work.

\section{Methods}

STUDY POPULATION

The study population consisted of male welders, metal workers, and office clerks of two companies involved in building large constructions - such as bridges and oilrigs. All employees in both companies were asked to participate in this study by giving their informed consent. All welders were involved in welding during most of their daily work. They performed their activities in welding booths as well as on site. About $90 \%$ of the work time was spent welding mild steel, although stainless steel was occasionally used. The group of metal workers consisted of those with various job titles, comprising caulker-burners, fitters, turners, sheet metal workers, plumbers, and grinders. The small group of office clerks consisted of managers, accountants, technical draughtsmen, and administrators.

\section{STUDY DESIGN AND DATA COLLECTION}

During 1993-4, study participants were interviewed by the occupational physician at entry into the study. The questionnaire included questions on age, height, weight, smoking history, duration of employment in current and previous jobs, and on respiratory and other complaints. ${ }^{9}$ These questions were derived from a standardised Nordic questionnaire on musculoskeletal complaints and a standardised questionnaire on respiratory symptoms..$^{10}{ }^{11}$

Questions asked about complaints of chronic cough, chronic sputum secretion, wheezing, shortness of breath, and attacks of chest tightness. Subjects who reported at least one of these symptoms were classified as prevalent cases of respiratory symptoms-namely, CNSLD-like symptoms. Asthma-like symptoms were derived from a positive answer on questions on wheezing for at least 1 week in the past 2 years, shortness of breath at any time in the past 2 years, or chest tightness in the morning at any time in the past 2 years. The COPDlike symptoms were defined as chronic cough or chronic phlegm for at least 3 months a year in the previous 2 consecutive years. The questionnaire also categorised workers into nonsmokers (never smoked), current smokers (currently smoking cigarettes, cigars, or pipes), and former smokers (formerly smoked regularly but stopped smoking for at least 1 year before the study). Those who stopped smoking less than 1 year before the study were classified as current smokers. The occupational health investigation was completed with a spirometric lung function test, which was performed with a Vicatest VCT- 5 spirometer. Measurements and procedures, including body temperature and pressure saturated adjustments, were carried out according to the standards of the European Respiratory Society and the American Thoracic Society. ${ }^{12}{ }^{13}$ Three readings of the forced vital capacity (FVC) and forced expiratory volume in 1 second $\left(\mathrm{FEV}_{1}\right)$ were recorded, with a minimum requirement of two reproducible curves $\left(\mathrm{FEV}_{1}\right.$ and FVC within 0.1 1). The highest FVC and $\mathrm{FEV}_{1}$ values were used from these readings and, subsequently, the Tiffeneau index was calculated. For each subject a predicted lung function variable was calculated with regression equations of the European Respiratory Society. ${ }^{14}$ All spirometry tests were performed by two qualified occupational nurses who had received a refresher course in spirometry.

During a 2 year follow up of each subject medical records were retrieved for information on frequency and duration of spells of sickness absence, and symptoms and diagnosis reported to have caused the sickness absence. The register of sickness absence recorded the occurrence and duration of every period of absence. If a worker fell ill, he was obliged to report his absence to the administration office. Subsequently, on the same day the worker was sent a short questionnaire with 24 questions on specific symptoms, which enabled the worker to report one or more complaints underlying his sickness absence. The questions on respiratory complaints were drawn from the standardised questionnaire on respiratory symptoms. ${ }^{11}$ Other questions pertained to common symptoms, such as cold, throat soreness, rhinitis, stomach complaints, muscle pain, raised temperature, and headache. Based on this self reported information, the occupational physician assigned the diagnosis to each spell of absence according to six groups; CNSLD, influenza, back disorder, other musculoskeletal disorders, miscellaneous disorders, and reasons unknown. This procedure was chosen as the company policy only required examination by the occupational physician of workers who had been absent for 2 weeks or more. Workers did not need to obtain a doctor's certificate in the first 2 weeks of absence. When for a particular sickness absence two health complaints were recorded, half of the sick days were attributed to either cause. The following outcomes of sickness absence per worker were collected: prevalence of absence (at least one period of sickness absence during the 2 year follow up), duration of absence (number of working days with sickness absence), frequency of absence (number of periods of sickness absence), and absence ratio (percentage of working days with sickness absence). In the last three measures workers without absence were excluded from the calculation of descriptive statistics. To avoid a strong influence of selective participation, respondents were excluded from the study if they had failed to return the sickness absence questionnaire more than once or if their sickness absence with unknown reason exceeded 10 working days. 
Table 1 Individual characteristics and working experience of welders, metal workers, and office workers at the start of the longitudinal study

\begin{tabular}{|c|c|c|c|c|c|c|}
\hline & \multicolumn{2}{|l|}{$\begin{array}{l}\text { Welders } \\
(n=97)\end{array}$} & \multicolumn{2}{|c|}{$\begin{array}{l}\text { Metal workers } \\
(n=125)\end{array}$} & \multicolumn{2}{|c|}{$\begin{array}{l}\text { Office workers } \\
(n=29)\end{array}$} \\
\hline & Mean & $S D$ & Mean & $S D$ & Mean & $S D$ \\
\hline \multicolumn{7}{|l|}{ Individual characteristics: } \\
\hline Age (y) & 41.5 & 10.3 & 39.8 & 9.6 & 39.9 & 9.8 \\
\hline Height $(\mathrm{cm})$ & 177.6 & 7.6 & 177.9 & 7.0 & 182.6 & 7.5 \\
\hline Weight (kg) & 79.2 & 11.4 & 79.3 & 10.6 & 83.0 & 10.0 \\
\hline \multicolumn{7}{|l|}{ Work history: } \\
\hline $\begin{array}{l}\text { Employment in current } \\
\text { company }(y)\end{array}$ & 13.8 & 7.9 & 13.3 & 7.8 & 9.7 & 7.0 \\
\hline Total working experience (y) & 20.2 & 11.7 & 21.7 & 10.7 & 18.7 & 11.9 \\
\hline \multicolumn{7}{|l|}{ Smoking history: } \\
\hline Smokers $(\mathrm{n},(\%))$ & $46(48)$ & & $49(40)$ & & $5(17)$ & \\
\hline Years smoking & 23.2 & 11.8 & 22.1 & 9.6 & 35 & 5.2 \\
\hline Ex-smokers (n, (\%)) & $26(27)$ & & $30(24)$ & & $8(28)$ & \\
\hline Years smoking & 17.4 & 7.9 & 18.5 & 9.4 & 12.3 & 5.9 \\
\hline
\end{tabular}

STATISTICAL ANALYSIS

The two principal outcomes of the study were time of follow up without sickness absence and duration of sickness absence due to respiratory complaints. Kaplan-Meier curves were produced to describe the proportion of workers without sickness absence relative to time since start of follow up, and the proportion of workers returning to work as a function of duration of sickness absence. Regression analysis based on the proportional hazards model was used to study prognostic factors simultaneously and to adjust for potential confounders. ${ }^{15}$ In the survival analysis on time without sickness absence due to respiratory complaints, right censoring of data was necessary as about $65 \%$ of the workers did not fall sick during the 2 year follow up period. For these workers, the observed time was less than the (unknown) actual event free time.

Univariate analyses were performed to examine the covariates age, height, weight, smoking habits, duration of total employment in the current job, company, job title, and duration of respiratory complaints. Likelihood ratio tests were applied to select the initial variables for inclusion in the multivariate analyses, with, as an inclusion criterion, a level of significance of 0.10 . The multivariate proportional hazards model included all variables that contributed significantly to the final model (Wald statistics, criterion of $\mathrm{p}<0.05)$. The dependent variable was the first spell of sickness absence due to respiratory complaints. Repeated events were excluded from these analyses. Age was included in each model, regardless of its level of significance. For each factor the hazard ratio

Table 2 Prevalence of respiratory complaints in the past 12 months before the start of the study among welders, metal workers and office workers

\begin{tabular}{|c|c|c|c|c|c|c|c|c|}
\hline & \multicolumn{2}{|c|}{$\begin{array}{l}\text { Welders } \\
(n=97)\end{array}$} & \multicolumn{2}{|c|}{$\begin{array}{l}\text { Metal workers } \\
(n=125)\end{array}$} & \multicolumn{2}{|c|}{$\begin{array}{l}\text { Office workers } \\
(n=29)\end{array}$} & \multicolumn{2}{|c|}{$\begin{array}{l}\text { Total } \\
(n=251)\end{array}$} \\
\hline & $n$ & $\%$ & $n$ & $\%$ & $n$ & $\%$ & $n$ & $\%$ \\
\hline Chronic cough & 13 & 14 & 7 & 6 & 0 & 0 & 20 & 8 \\
\hline Chronic sputum secretion & 12 & 13 & 7 & 6 & 3 & 11 & 22 & 9 \\
\hline Shortness of breath & 4 & 4 & 6 & 5 & 1 & 4 & 11 & 5 \\
\hline Ever wheezing & 22 & 23 & 17 & 14 & 5 & 17 & 44 & 18 \\
\hline Wheezing $>1$ week in the past 2 years & 12 & 13 & 6 & 5 & 4 & 14 & 22 & 9 \\
\hline Chest tightness & 11 & 12 & 3 & 3 & 2 & 7 & 16 & 7 \\
\hline \multicolumn{9}{|l|}{ Disorders according to questionnaire: } \\
\hline Asthma & 17 & 18 & 11 & 9 & 4 & 14 & 32 & 13 \\
\hline Chronic obstructive pulmonary disease & 15 & 16 & 9 & 7 & 3 & 11 & 27 & 11 \\
\hline Chronic non-specific lung disease & 23 & 25 & 15 & 12 & 4 & 14 & 42 & 17 \\
\hline Airways allergy & 11 & 12 & 20 & 16 & 4 & 14 & 35 & 14 \\
\hline
\end{tabular}

and $95 \%$ confidence interval (95\% CI) were calculated. The hazard ratio is interpreted as the relative risk (RR) at any time during the follow up. All statistical analyses were performed with SPSS software. ${ }^{16}$

\section{Results}

RESPONSE

The initial response to participate in the study was $88 \%$ (326 respondents). Baseline spirometric tests were completed by 306 workers $(85 \%)$. During the follow up 23 workers $(7 \%)$ left the company and 43 workers $(13 \%)$ had incomplete data on causes of sickness absence, primarily due to non-response on the short questionnaire during sickness absence. The total study population with complete 2 year follow up consisted of 251 people. A nonresponse analysis showed that the 66 workers who did not complete follow up had a higher prevalence of CNSLD complaints at baseline than those who completed the follow up, 33\% and $17 \%$ respectively. Workers with incomplete sickness absence data $(n=43)$ had a higher sickness absence both in frequency and total duration than the workers in the study population, although any differences in respiratory sickness absence could not be determined. The 66 workers lost to follow up did not differ in individual characteristics and working experience from those who completed the follow up.

\section{BASELINE CHARACTERISTICS}

Table 1 shows the basic characteristics of the 251 workers with complete data in the study population. The population consisted predominantly of middle aged men, although age ranged from 19 to 59 . The occupational groups did not differ for individual characteristics and distributions of duration of employment in current and previous jobs. About $86 \%$ had had previous jobs and most of the previous positions held were comparable with the current occupation. Between welders and metal workers there was no significant difference in current smokers and years of smoking but there was a significant difference between office workers and the two blue collar groups. Ex-smokers $(25.5 \%)$ stopped smoking, on average, almost 10 years before the study in all the groups.

The predominant respiratory complaint in the 12 months before the study was wheezing (18\%) followed by chronic sputum secretion $(9 \%)$, prolonged wheezing $(9 \%)$, and chronic cough $(8 \%)$ (table 2). Other complaints were less common; the same was true for work related symptoms. One out of four smokers had respiratory complaints. Welders had more complaints than the other groups but these differences did not reach conventional levels for significance except for chronic cough $\left(\chi^{2}\right.$ test, $\mathrm{p}=0.02)$ and chest tightness $\left(\chi^{2}\right.$ test, $\left.\mathrm{p}=0.02\right)$. The prevalence of CNSLD was significantly higher in welders $\left(\chi^{2}\right.$ test, $\left.p=0.05\right)$ but this was not so for asthmatic complaints and COPD. Smoking was correlated with complaints like chronic cough and chronic sputum secretion but not with chest tightness and prolonged wheezing. This resulted in a significantly higher 
Table 3 Sickness absence due to respiratory complaints during the 2 year follow up among 251 welders, metal workers, and office workers

\begin{tabular}{llll}
\hline & $n$ & Mean & Range \\
\hline Asthma-like complaints: & & & \\
$\quad$ Prevalence (workers (n)) & 46 & & \\
$\quad$ Frequency (absence periods (n)) & 84 & 1.82 & $1-7$ \\
Duration (work days of absence) & 84 & 6.47 & $1-23$ \\
$\quad$ Ratio (work days with sickness absence (\%)) & 46 & 2.69 & $0.45-13.0$ \\
Complaints of chronic obstructive pulmonary disease: & & & \\
Prevalence (workers (n)) & 79 & & \\
Frequency (absence periods (n)) & 122 & 1.54 & $1-5$ \\
Duration (work days of absence) & 122 & 8.35 & $1-252$ \\
$\quad$ Ratio (work days with sickness absence (\%)) & 79 & 3.23 & $0.23-61.4$ \\
Complaints of chronic non-specific lung disease: & & & \\
Prevalence (workers (n)) & 88 & & \\
Frequency (absence periods (n)) & 157 & 1.78 & $1-7$ \\
Duration (work days of absence) & 157 & 7.63 & $1-252$ \\
Ratio (work days with sickness absence (\%)) & 88 & 3.10 & $0.23-61.4$ \\
\hline
\end{tabular}

prevalence of COPD $\left(\chi^{2}\right.$ test, $\left.\mathrm{p}=0.01\right)$ and CNSLD $\left(\chi^{2}\right.$ test, $\left.\mathrm{p}=0.04\right)$ in smokers but this was not so for asthma.

SICKNESS ABSENCE

Among the 251 people with sufficient data during the study, 39 (15.5\%) did not take any sick leave at all. During the follow up over 2 years, $212(84.5 \%)$ workers were absent from work due to sickness for one or more periods, resulting in a total of 816 sickness absence periods ranging between 1 and 14 periods per person (mean $=3.89$ ). During the 2 year follow up the sickness absence ratio in the study population was $7.7 \%$ with non-specific respiratory complaints accounting for $14.2 \%$ of the days lost. Musculoskeletal disorders accounted for $43.8 \%$ of all days lost, influenza $19.0 \%$, other causes $19.9 \%$, and unknown causes $3.1 \%$.

Table 3 shows the prevalence, frequency, duration, and ratio of sickness absence due to respiratory complaints. These results have been calculated for people with at least one sickness period due to CNSLD. During the 2 year follow up the proportion of workers that experienced at least one period of sickness absence as a result of asthma-like symptoms was $18 \%$, COPD-like symptoms $31 \%$ and, in general from CNSLD-like symptoms 35\%. The distribution of time at work before a first sickness

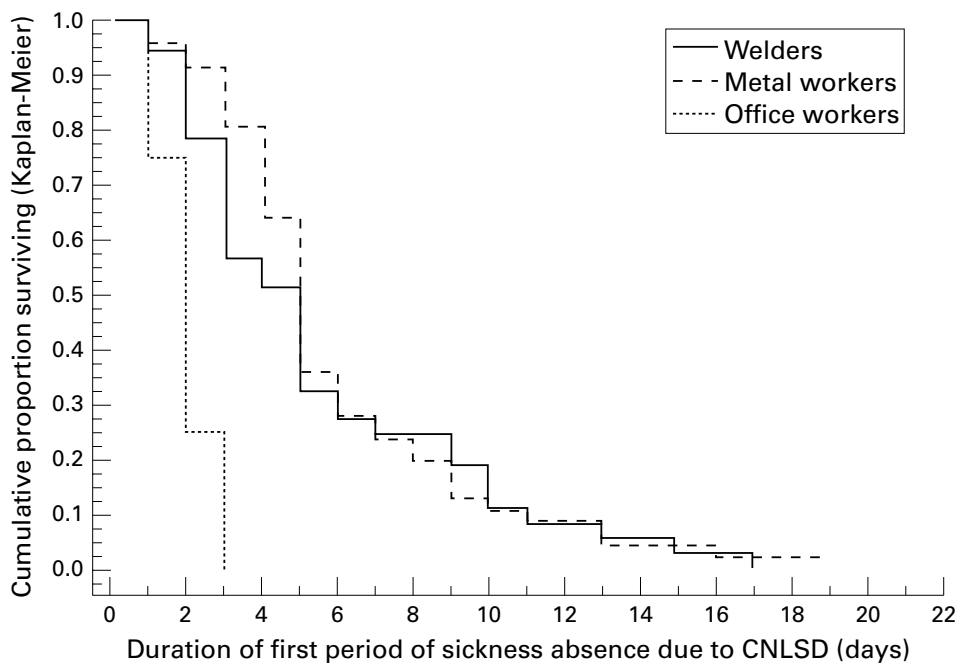

Time to return to work after a first period of sickness absence due to respiratory complaints absence due to these complaints differed significantly between the occupational groups.

As can be seen from the frequencies of sickness absence in table 3, several workers were absent more than once for the same complaint. The probability of a recurrent sickness absence within 1 year was significantly higher than the probability of a first sickness absence within 1 year. For asthmatic complaints a 1 year recurrence rate of $25 \%$ was found, for complaints about COPD 35\%, and for complaints about CNSLD $43 \%$.

The distribution of the duration of sickness absence did not differ among the specific disorders. The figure shows the return to work for workers who lost any time off work because of a first spell of respiratory complaints (between occupational groups). Almost no difference was found in rates of return to work between first periods and subsequent periods of sickness absence due to respiratory complaints. Most workers $(67 \%)$ returned to work within 5 working days (1 week) and almost all $(90 \%)$ returned within 10 days (about 2 weeks), although those with asthmatic complaints returned to work later $(55 \%$ in the first 5 days and $87 \%$ in the first 10 days). Only in three cases $(2 \%)$ did the duration of sickness absence exceed 20 days ( 1 month) and all came for workers with more than one absence.

\section{PROGNOSTIC FACTORS}

Table 4 presents the factors associated with the occurrence of sickness absence due to respiratory complaints during the 2 year follow up. The presence of asthmatic complaints in the 12 months before the study was a significant predictor for sickness absence due to asthma-like symptoms (RR 3.96; 95\% CI 1.99 to 7.90 ). However complaints about COPD and CNSLD were not associated with an increased probability of sickness absence during follow up. For the prognostic value of severe limitation of lung function, decrease in FVC $(<80 \%$ of the reference value) contributed to the prediction of sickness absence due to asthma and CNSLD but not for COPD although the risk was increased (RR $1.77 ; 95 \%$ CI 0.71 to 4.42 ). The other indexes of lung function $\left(\mathrm{FEV}_{1}\right.$ and Tiffeneau index) were not significant predictors. In none of the multivariate models was age a significant risk factor. Smoking was not a significant factor for sickness absence from any cause. From the other individual characteristics only the duration of employment was associated with the probability of not taking sick leave (RR 0.94; 95\% CI 0.91 to 0.97). This was true for all causes.

Table 5 shows the prognostic factors for return to work after a period of sickness absence. Metal workers and welders with COPD and CNSLD had a significantly decreased chance of returning to work quickly compared with the reference group despite the few office workers. Individual characteristics and work history were not associated with the probability of return to work. 
Table 4 Multivariate hazards RRs (95\% CIs) of prognostic factors for the occurrence of sickness absence due to respiratory disorders

\begin{tabular}{|c|c|c|c|c|}
\hline Cause of sickness absence and factor & Subjects & $R R$ & $(95 \% C I)$ & $p$ Value \\
\hline \multicolumn{5}{|l|}{ Asthma: } \\
\hline \multicolumn{5}{|l|}{ Age $(y)$ : } \\
\hline$\leqslant 40$ & 125 & 1.00 & & \\
\hline$>40$ & 126 & 0.65 & $(0.35$ to 1.22$)$ & 0.18 \\
\hline \multicolumn{5}{|l|}{ FVC: } \\
\hline$>80 \%$ Of reference FVC & 228 & 1.00 & & \\
\hline$\leqslant 80 \%$ Of reference FVC & 10 & 4.03 & (1.41 to 11.54$)$ & 0.009 \\
\hline \multicolumn{5}{|l|}{ Asthma complaints before study: } \\
\hline No & 219 & 1.00 & & \\
\hline Yes & 32 & 3.96 & (1.99 to 7.90$)$ & 0.000 \\
\hline \multicolumn{5}{|c|}{ Chronic obstructive pulmonary disease: } \\
\hline \multicolumn{5}{|c|}{ Age (y): } \\
\hline$\leqslant 40$ & 125 & 1.00 & & \\
\hline$>40$ & 126 & 0.78 & $(0.49$ to 1.25$)$ & 0.31 \\
\hline Office workers & 29 & 1.00 & & \\
\hline$v$ Metal workers & 125 & 2.77 & (0.99 to 7.75$)$ & 0.05 \\
\hline$v$ Welders & 97 & 2.73 & $(0.95$ to 7.79$)$ & 0.06 \\
\hline \multicolumn{5}{|l|}{ Chronic non-specific lung disease: } \\
\hline \multicolumn{5}{|l|}{ Age $(y)$ : } \\
\hline$\leqslant 40$ & 125 & 1.00 & & \\
\hline$>40$ & 126 & 0.69 & $(0.44$ to 1.08$)$ & 0.1 \\
\hline \multicolumn{5}{|l|}{ FVC: } \\
\hline$>80 \%$ Of reference FVC & 228 & 1.00 & & \\
\hline$\leqslant 80 \%$ Of reference $\mathrm{FVC}$ & 10 & 2.49 & (1.07 to 5.79$)$ & 0.034 \\
\hline Office workers & 29 & 1.00 & & \\
\hline$v$ Metal workers & 125 & 2.91 & (1.04 to 8.13$)$ & 0.04 \\
\hline$v$ Welders & 97 & 3.52 & (1.24 to 9.97$)$ & 0.018 \\
\hline
\end{tabular}

Table 5 Multivariate hazards RRs (95\% CIs) of prognostic factors for return to work after sickness $\mathrm{v}$ welders's absence due to respiratory disorders

\begin{tabular}{|c|c|c|c|c|c|}
\hline $\begin{array}{l}\text { Cause of sickness } \\
\text { absence }\end{array}$ & Factor & Subjects & $R R$ & $(95 \% C I)$ & $p$ Value \\
\hline \multicolumn{6}{|l|}{ Asthma: } \\
\hline \multicolumn{6}{|l|}{ Age (y): } \\
\hline$\leqslant 40$ & & 26 & 1.00 & & \\
\hline$>40$ & & 20 & 1.06 & $(0.53$ to 2.14$)$ & 0.86 \\
\hline Office workers & & 2 & 1.00 & & \\
\hline$v$ Metal workers & & 25 & 4.90 & (1.04 to 23.13$)$ & 0.04 \\
\hline$v$ Welders & & 19 & 4.77 & $(0.97$ to 23.4$)$ & 0.05 \\
\hline \multicolumn{6}{|c|}{ Chronic obstructive pulmonary disease: } \\
\hline \multicolumn{6}{|c|}{ Age $(y)$ : } \\
\hline$\leqslant 40$ & & 43 & 1.00 & & \\
\hline$>40$ & & 36 & 1.00 & $(0.60$ to 1.65$)$ & 0.99 \\
\hline Office workers & & 4 & 1.00 & & \\
\hline$v$ Metal workers & & 45 & 5.53 & (1.83 to 16.73$)$ & 0.002 \\
\hline$v$ Welders & & 30 & 4.79 & (1.56 to 14.71$)$ & 0.006 \\
\hline \multicolumn{6}{|c|}{ Chronic non-specific lung disease: } \\
\hline \multicolumn{6}{|c|}{ Age $(y)$ : } \\
\hline$\leqslant 40$ & & 50 & 1.00 & & \\
\hline$>40$ & & 38 & 0.90 & $(0.55$ to 1.47$)$ & 0.67 \\
\hline Office workers & & 4 & 1.00 & & \\
\hline$v$ Metal workers & & 47 & 6.43 & (2.08 to 19.85$)$ & 0.001 \\
\hline$v$ Welders & & 37 & 5.74 & (1.90 to 17.4$)$ & 0.002 \\
\hline
\end{tabular}

\section{Discussion}

Data on the natural course of respiratory disorders and subsequent sickness absence are sparse..$^{5-8}$ This study among blue collar and white collar workers showed that over a 2 year period about $35 \%$ of the workers attributed at least one episode of sickness absence to respiratory complaints. The impact of respiratory disorders on the workforce was also illustrated by the finding that these disorders accounted for $20 \%$ of all absence periods during the follow up but for $14.2 \%$ of the days lost. The 1 year rate of absence due to CNSLD was $21 \%$, for COPD it was $17.5 \%$, and for asthma it was $10.5 \%$. These numbers comply well with the published information. ${ }^{28}$ However, these studies were based on self reports rather than sickness absence registries and some bias may have occurred. As expected, there was also increased risk for recurrent periods of absence for CNSLD. The 1 year recurrence rates for particular respiratory sickness absences were about twice the 1 year period prevalences, indi- cating that workers with previous temporary disability from respiratory problems are at higher risk of subsequent sickness absence.

The prevalences of particular respiratory complaints in the 12 months before the baseline survey were between $5 \%(n=11)$ and $18 \%(n=44)$ in the total population $(n=251)$. There were no significant differences between blue collar and white collar workers, and the prevalences were within the range of reported prevalences in occupational groups of blue collar workers. ${ }^{8}{ }^{17} 18$ Of all workers with respiratory symptoms, about half reported only symptoms related to specific working conditions (20 out of 42). This is in agreement with published results. ${ }^{19}$ There was a substantial overlap between the asthma-like diagnosis and the COPD-like diagnosis, indicating that respiratory complaints do not distinguish sharply between these diagnoses. The lack of significant differences between blue collar and white collar workers may be due to the healthy worker effect. There was a difference between welders and metal workers which may reflect differences in work activities and working conditions. The non-response may also have contributed to the moderate prevalence of respiratory complaints because the analysis of non-response showed that in both groups sickness absence was higher in non-respondents than in the subjects participating in this study.

The well known role of smoking in the occurrence of respiratory complaints, was partially confirmed in the survey. ${ }^{20}{ }^{21}$ Current smoking was strongly associated with respiratory complaints only in metal workers. That was true especially for COPD-like complaints. There was a weaker association for welders and none for office workers. Former smokers resembled lifetime non-smokers, which could be explained by the finding that former smokers, on average, had stopped smoking for almost 10 years. The relation between age and respiratory complaints was ambiguous. Among the office workers there was a declining trend, whereas the blue collar workers had an increased prevalence with age. That was true especially for COPD. Interpretation of these patterns is difficult. A possible cause could be that the respiratory symptoms included asthma and chronic obstructive pulmonary disease, which have different associations with age. Asthma expresses itself generally at an early age, whereas chronic bronchitis arises more often in older subjects. More likely, different mechanisms of a healthy worker selection play an important part. Because age and duration of employment were strongly correlated, duration of employment had similar patterns of association with respiratory complaints.

In the regression analysis several factors were evaluated for their influence on the probability of occurrence of sickness absence due to respiratory disorders. Individual characteristics such as age, height, and weight were not predictive for respiratory disorders leading to absence from work. Current smoking did not affect absenteeism due to respiratory complaints. Duration of employment had a slight protective effect in absence due to respiratory 
complaints. Decreased $\mathrm{FEV}_{1}$ was not predictive for respiratory absence, by contrast with the findings of other studies..$^{5-8}$

The limited size of the study population hampers detailed analyses and also introduced large $95 \%$ CIs, which prevents risk factors from reaching significance. This was particularly the case in the analysis of factors associated with respiratory absence. Therefore, it was not feasible to investigate the influence of important factors such as overall health, morbidity, and work requirements on the sickness absence due to respiratory diseases. ${ }^{1}$

Workers with respiratory symptoms were absent more often due to respiratory symptoms than those without. This difference reached a conventional level of significance only for absence due to asthmatic complaints. These findings are not in full agreement with the few publications on this matter. ${ }^{5-8}$

Previous asthmatic complaints were very significant predictors of future sickness absence due to these complaints. Both complaints about CNSLD and work related CNSLD were also significant predictors of absence due to asthmatic complaints. Surprisingly, the occurrence of complaints about COPD and CNSLD in the 12 months before the study was not associated in a significant level with absence for these complaints. This contrasts with the common finding that a history of COPD or CNSLD is a strong risk factor for recurrent complaints and sickness absence..$^{5-8} \mathrm{~A}$ possible explanation for this contradictory result might be that subjects whose complaints followed a less severe but unremitting chronic course were overrepresented among those lost to follow up. The nonresponse analysis showed that subjects who dropped out of the study during the follow up reported significantly more COPD during the baseline survey than those who completed the study.

Job titles were predictors for sickness absence for all kinds of respiratory complaints. This may reflect differences in work activities and working conditions between jobs. Other prognostic factors described in the scientific literature-such as poor working relations, management policy, and worker's avoidance behaviour, ${ }^{122}$ are less likely to explain these results as these risk factors would have entertained a similar systematic effect on all three categories of respiratory complaints.

The available information on return to work after an episode of respiratory sickness absence is based on small numbers. Hence, the statistical analysis provided limited insight into possible prognostic factors for return to work. Moreover, the study population of welders and metal workers may lack sufficient contrast in exposure and health status to ascertain their impact on return to work. It should be borne in mind that the current study included all cases of respiratory absence, irrespective of the duration of absence and whether the subjects off work sought medical care. Within the framework of the study it was not feasible to conduct a clinical evaluation of every case at the onset of absence. Hence, the results in this longitudinal study among workers may differ from incep- tion cohort studies based on groups of patients enrolled in general practice or compensation systems shortly after the onset of symptoms. Studies on patients with CNSLD have identified predictors for delayed return to work. These include several clinical variables of the complaint and effect modifiers-such as mental health, poor job satisfaction, and pursuit of compensation. ${ }^{22}$

The risks of becoming ill due to CNSLD were similar but less than the risks of delayed return to work. Only job title was a significant predictor for delayed return to work. By contrast with incidence of absence, metal workers had a higher risk of delayed return to work than welders or office personnel. No significant differences were found among the distributions of duration of sickness absence for particular respiratory complaints. On average, about $67 \%$ of the workers returned to work within 1 week ( 5 working days), and about $90 \%$ returned to work within 2 weeks ( 10 working days; figure). This high return to work within the first weeks suggests that any medical programme aimed at early intervention will most likely be only cost effective when the treatment has a very strong effect. The differences between blue collar and white collar workers were based on very small numbers. Although there was a small difference between the distributions of return to work after a first period of sickness absence and after a repeat period of sickness absence, it was not significant. Although the information on duration of recurrent episodes of sickness absence was based on only 39 events, this finding does not support the hypothesis that subjects off work for recurrent periods have passed through earlier stages of disability with less lost time. Among welders and metal workers, subjects with respiratory sickness absence were at increased risk of a recurrent episode but this second episode did not delay return to work. In this study it was not possible to distinguish between complete recovery from respiratory complaints and return to work, as the presence of residual respiratory complaints when resuming work was not ascertained. Perhaps full recovery and return to work are outcomes that should be differentiated. In this study return to work and recovery may have been similar as workers did not experience any cut in their regular wages within the first few weeks of sickness absence.

This longitudinal study has several limitations, most of them related to the inability to perform clinical assessments of the complaints underlying respiratory sickness absence. However, the results showed that a history of complaints about asthma and CNSLD in the 12 months before the study was associated with subsequent sickness absence for asthmatic complaints during the follow up. Also, workers with absence due to respiratory disorders were at higher risk of subsequent sickness absence in the next year. It is important to study temporal associations between the occurrence of respiratory complaints and subsequent disability. In this respect, health complaints, sickness absence, and return to work should be studied simultaneously in the same occupational populations. 
ECA was partially supported by a grant from the State Scholarships Foundation of Greece while pursuing his MSc in Epidemiology at the Netherlands Institute for Health Sciences in Rotterdam.

1 Feeney A, North F, Head J, et al. Socioeconomic and sex differentials in reason for sickness absence from the Whitehall II study. Occup Environ Med 1998;55:91-8.

2 Szubert Z, Szeszenia-Dabrowska N, Sobala W. Sickness absence in a rubber plant in Poland. Int $\mathcal{F}$ Occup Med Environ Health 1998;11:179-88.

3 Ritchie KA, Macdonald EB, Gilmour WH, et al. Analysis of sickness absence among employees of four NHS trusts. Occup Environ Med 1999;56:702-8.

4 Indulski JA, Szubert Z. Female sickness absenteeism in Poland. Int f Occup Med Environ Health 1996;9:219-25.

5 Gocke TM, McPherson P, Webb NC. Predicting respiratory absenteeism. Arch Environ Health 1965;10:332-7.

6 Jedrychowski W. Sickness absence caused by chest diseases in relation to smoking and chronic bronchitis symptoms. $B$ in relation to smoking and

7 Comstock GW, Stone RW, Tonascia JA, et al. Respiratory survey findings as predictors of disability from respiratory diseases. Am Rev Respir Dis 1981;124:367-71.

8 Post WK, Burdorf A, Bruggeling TG. Relations between respiratory symptoms and sickness absence among workers in the animal feed industry. Occup Environ Med 1994;51: $440-6$.

9 Burdorf A, Post W, Bruggeling T. Reliability of a questionnaire on sickness absence with specific attention to absence due to back pain and respiratory complaints. Occup Environ Med 1996;53:58-62.

10 Kuorinka I, Jonsson B, Kilbom A, et al. Standardised Nordic questionnaire for the analysis of musculoskeletal symptoms. Appl Ergon 1987;18:233-7.
11 Minette A. Questionnaire of the European Community for Coal and Steel on respiratory symptoms. 1987: Updating of the 1962 and 1967 questionnaires for studying chron bronchitis and emphysema. Eur Respir 7 1989;2:165-77.
Quanjer PH, ed. Standardized lung function testing. Report of the working party standardization of lung function tests. Bulletin Europeen de Physiopathologie Respiratoire 1983; 19(suppl 5):1-95.1]

13 American Thoracic Society. Standards for the diagnoses and care of patients with chronic obstructive pulmonary disease (COPD) and asthma. Am Rev Respir Dis 1987;119:831-8.

14 Quanjer PH, Tammeling GJ, Cotes JE, et al. Lung volumes and forced ventilatory flows. Eur Respir F 1996;6 (suppl 16): $5-40$.

15 Cox DR, Oakes D. Analysis of survival data. London: Chapman and Hall, 1984.

16 SPSS. SPSS/PC+ System user guide, version 5.0. Chicago, Illinois: SPSS, 1992 .

17 Lundback B, Stjernberg N, Nystrom L, et al. Epidemiology of respiratory symptoms, lung function and important determinants. Report from the obstructive lung disease in northern Sweden project. Tuber Lung Dis 1994;75:116-26.

18 Chinn DJ, Stevenson IC, Cotes JE. Longitudinal respiratory survey of shipyard workers: effects of trade and atopic status. Br F Ind Med 1990;47:83-90.

19 Musk AW, de Klerk NH, Beach JR, et al. Respiratory symptoms and lung function in alumina refinery employees. Occup Environ Med 2000;57:279-83.

20 Sherman CB. The health consequences of cigarette smoking. Pulmonary diseases. Med Clin North Am 1992;76:355-75.

21 Smith GC, Athanasou JA, Reid CC, et al. Sickness absence, respiratory impairment, and smoking in industry: an Australian study. Med f Aust 1981;1:235-7.

22 Hunt HA, Habeck RV. The Michigan disability prevention study. Research highlights. Kalamazoo, MI: Upjohn Institute for Employment Research, 1993.

\section{Open reviewing}

Many journals, including the BMJ, have moved to a system of open reviewing, whereby authors know the names of reviewers of their papers. Research has shown that named reviews, although not of better quality than anonymous reviews, are not of worse quality either. Therefore in the interests of transparency, it seems fair to let authors know who has reviewed their paper. At Occupational and Environmental Medicine we have considered the issue carefully. There are some concerns that reviewers, especially those who are more junior, might feel intimidated and not wish to make negative comments about papers submitted by senior people in the field. On the other hand, some reviewers might hide behind the cloak of anonymity to make unfair criticisms so as to reduce the chances of publication by rivals. We have decided to introduce initially a system of open reviewing if the reviewers agree explicitly. So when a reviewer is sent a paper, he or she is asked to indicate whether we can disclose their name or not when sending the authors their comments. We will be monitoring this to see how many of our reviewers are happy to be named. If it is most of them, we will move to a system of open reviewing as the norm, with a possible "opt out" clause for reviewers. 